\title{
An Alumina Standard Reference Material for Resonance Frequency and Dynamic Elastic Moduli Measurement II. Characteristic Values for Use from $25^{\circ} \mathrm{C}$ to $1000^{\circ} \mathrm{C}$
}

\author{
Robert W. Dickson and Edward Schreiber* \\ National Bureau of Standards, Washington, D.C. 20234
}

(February 16, 1973)

\begin{abstract}
The temperature dependence of Young's modulus and the shear modulus of polycrystalline alumina is given over the range of 25 to $1000^{\circ} \mathrm{C}$. Results are expressed in terms of the dimensionless ratio: modulus value at temperature divided by modulus value at $25^{\circ} \mathrm{C}$. These results are intended for use with Standard Reference Material No. 718 which is intended for calibration of apparatus used to determin elastic moduli of solids by a resonance technique. The worst agreement is $9.5 \times 10^{-4}$ for the flexure and $19.1 \times 10^{-4}$ for the torsion, between any two individual measurements, and we recommend these as the minimum acceptable limits in using the standards.
\end{abstract}

Key words: Alumina; elastic modulus; resonance frequency; shear modulus; standard reference material; Young's modulus.

\section{Introduction}

The elastic moduli of homogeneous, isotropic, solids are often calculated from the resonance frequencies of a slender bar or rod of the material excited in either flexure or torsion [1] ${ }^{1}$. In principle the moduli are calculated directly from the resonance frequencies and the dimensions and density of the sample. However, as discussed in Part I [2], the corrections required for the effect of loading or damping by the suspensions and the atmosphere are difficult to calculate, and it is frequently convenient to have available a standard bar whose resonance has been accurately determined to use in order to estimate or confirm the errors in a particular experimental apparatus.

To meet this need, NBS has made available a series of carefully prepared bars of polycrystalline alumina whose fundamental resonance frequencies in free vibration in both torsion and flexure have been measured. In Part I the bars themselves and the room temperature measurements are described. In this section we report the results of measurements as a function of temperature from room temperature to $1000{ }^{\circ} \mathrm{C}$. At the higher temperatures it is very laborious to ensure that the temperature throughout the sample is uniform and equal to that measured, since the sensing instrument cannot be in direct contact with the sample without causing additional changes in resonance

\footnotetext{
*Present address: Department of Earth Environmental Sciences, Queens College, Flushing, New York 11367. Also, Senior Research Associate (Visiting), Lamont-Doherty Geological Observatory, Palisades, New York 10964.

${ }^{1}$ Figures in brackets indicate the literature references at the end of this paper.
}

frequency. Fortunately it proved unnecessary w measure the temperature variation of each bar in the set since the ratio of the resonant frequencies at two temperatures is almost identical for all bars in the set. This was demonstrated by comparing the ratios measured on two bars, A-1 and C-7, whose densities and resonant frequencies are close to the minimum and maximum values for the set (the densities of $88 \%$ of all bars fall between the densities of these two samples).

By expressing the temperature variation in terms of ratios of resonant frequencies instead of the frequencies themselves, many of the corrections which would be very difficult to apply at high temperatures become insignificant. Hence the attention in this work could be concentrated on (l) suspending the specimen in a furnace in such a way as to obtain a good response, and (2) maintaining the test specimen at a fixed temperature and measuring that temperature accurately. The principle source of error of the frequency ratios is the measurement of the test temperature.

\section{Experimental Procedure}

The ratio of Young's and shear moduli at temperature $T\left(Y_{T^{\prime}} G_{T}\right)$ and reference temperature of $25^{\circ} \mathrm{C}\left(Y_{0^{\prime}} G_{0}\right)$ is given in terms of the corresponding frequency ratio, $F_{i}^{T}\left(=f_{i}^{T} \mid f_{i}^{0}\right.$, with $i=Y$ or $\left.G\right)$ by

$$
Y_{T} / Y_{0}=\left(F_{Y}^{T}\right)^{2} \frac{l_{0}}{l_{0}+\Delta l} ; G_{T} / G_{0}=\left(F_{G}^{T}\right)^{2} \frac{l_{0}}{l_{0}+\Delta l},
$$


where $\frac{\Delta l}{l_{0}}$ is the relative change in linear dimensions of the sample between the reference temperature and the temperature of measurement. This equation is equivalent to that given by Ault and Ueltz [3] for calculating Young's modulus and discussed by Spinner [4] for the general case including both Young's and shear moduli.

In order to establish the validity of the assumptions stated in the previous section concerning the advantages of using the parameter $\left(F_{i}^{T}\right)$, and to provide an independent crosscheck, the two bars, A-1 and C-7, were run on the apparatus at the National Bureau of Standards, and bar A-1 was also run using a similar type apparatus at the Lamont-Doherty Geological Observatory (LDGO). The electronic apparatus used by the Bureau was described in Part I [2]. Differences arose in the method of suspending the specimen, arrangement of thermocouples, and furnace design. Platimum-Platimum +10 percent Rhodium thermocouples were used as temperature sensors, in conjunction with a sensitive potentiometer. The arrangement used at NBS will be described first. The furnace used was a platinum wound tube furnace designed to provide a wide zone of constant temperature both axially and radially. The furnace was enclosed in a water-cooled gas tight jacket. The specimen was suspended from the driver and pickup needles with fine nichrome wire as shown in figure 2 of Dickson and Spinner [5]; the position of the suspending wires on the specimen was as described in Part I [2]. The measurements were performed in argon under a pressure of $1 \mathrm{~mm} \mathrm{Hg}$ for the reasons described in Part I. The thermocouple arrangement for the calibration runs and the data runs were as follows:

Four thermocouples were used, three for monitoring and one for controlling the furnace temperature. Both the control thermocouple and the principal monitoring thermocouple were located near the center of the specimen and approximately $5 \mathrm{~mm}$ below it; the secondary monitoring thermocouples were located below and near the ends of the specimen. Prior to the frequency determinations a dummy alumina specimen of the same nominal dimensions as the standard bars was suspended in the manner and position which were to be used for the frequency determinations, but substituting thermocouples for the nichrome suspension wires. The beads of these thermocouples were in contact with the specimen, allowing the actual specimen temperature to be observed. The furnace was then closed and the temperature distribution observed over the range of interest under varying pressures of argon. The small gradients observed varied with both temperature and gas pressure, $200 \mathrm{~mm}$ pressure of argon was chosen for the frequency determinations as being the most suitable over the entire temperature range of interest. A correction to be applied to the temperature observed with the monitoring thermocouples was then determined which was used during the frequency determinations to convert observed temperature to specimen temperature. This correction was a smoothly vary- ing function of temperature with a maximum value of $5.7^{\circ} \mathrm{C}$.

A standard bar with the normal suspension was then introduced into the furnace and the flexural and torsional resonance frequencies determined over the temperature range of interest. Care was taken to fill the aperture through which the suspension wires entered the furnace as completely as possible with fire brick to minimize the temperature gradients. With the long wire suspensions some difficulty was encountered with spurious resonances in the system; for a given suspension these were troublesome only over a limited temperature range. To overcome this, the suspect data were carefully weeded out and the frequencies redetermined until valid data were obtained over the entire range.

Since different suspensions gave slightly different reference temperature values for the frequency, the data were analyzed in terms of $\left(F_{\imath}^{T}\right)^{2}$, the quantity of interest. To do this, a straight line was arbitrarily chosen to pass through 1.000 at $25^{\circ} \mathrm{C}$ and the approximate value of $\left(\boldsymbol{F}_{l}^{T}\right)^{2}$ at $1000^{\circ} \mathrm{C}$. The difference between the observed values of $\left(F_{l}^{T}\right)^{2}$ and this straight line was at no point greater than 0.003 and when plotted versus temperature, yielded a set of points to which a smooth curve could be fitted by eye. The values given in table I were obtained from the curves thus obtained.

The furnace used at LDGO was a glo-bar box furnace with a six inch zone of constant temperature. The specimen was suspended from above using fine nichrome wires as shown in figure 1 of Dickson and Spinner [5] and located slightly displaced from the nodal positions for flexure. While this procedure introduces a slight shift in the measured frequency from that for free vibrations, it does not constitute an error in the normalized frequency since this is relatively insensitive to the position of the suspending fibers so long as their position remains constant throughout the experiment. In this apparatus, the runs were performed in air at 1 atm pressure. Thus a cross check was provided on the pressumed elimination of loading effects in the normalized frequency data. Four thermocouples were employed. One was placed at each end of the specimen to check on the thermal gradient across the length of the specimen. These were wired to yield a differential output. The third and fourth thermocouples were tied together and located at the middle and slightly above the specimen. One of these was used to determine the specimen temperature, the other to operate the temperature controller unit. All four thermocouples were positioned to within $1 / 4$ in of the specimen. Considerable care was taken in suspending the specimen in the furnace and locating the thermocouples, particularly after replacing the insulation into the opening through which the specimen and thermocouples were emplaced. This was facilitated by the design of the furnace which had removable bricks at the ends, allowing access for making minor adjustments in locating the specimen and thermocouples after all other components were in place. All furnace openings were completely covered with insulating 
TABLE 1. Dependence of normalized frequencies of standard alumina bars on temperature

\begin{tabular}{|c|c|c|c|c|c|c|c|c|c|c|}
\hline \multicolumn{6}{|c|}{$F_{Y}^{T}=\left(f \mid f_{25}\right)^{2}$ from flexure } & \multicolumn{5}{|c|}{$F_{G}^{T}=\left(f / f_{25}\right)^{2}$ from torsion } \\
\hline$\underset{{ }^{\circ} \mathrm{C}}{\text { Temp. }}$ & $\begin{array}{l}\text { C-7 } \\
\text { NBS }\end{array}$ & $\begin{array}{l}\text { A-1 } \\
\text { NBS }\end{array}$ & $\begin{array}{l}\text { A-1 } \\
\text { LDGO }\end{array}$ & Av. & \begin{tabular}{|c|} 
Maximum \\
spread of \\
values \\
$\times 10^{4}$
\end{tabular} & $\begin{array}{l}\text { C-7 } \\
\text { NBS }\end{array}$ & $\begin{array}{l}\text { A-1 } \\
\text { NBS }\end{array}$ & $\begin{array}{c}\text { A-1 } \\
\text { LDGO }\end{array}$ & Av. & $\begin{array}{l}\text { Maximum } \\
\text { spread of } \\
\text { values } \\
\times 10^{4}\end{array}$ \\
\hline 25 & 1.00000 & 1.00000 & 1.00000 & 1.00000 & - & 1.00000 & 1.00000 & 1.00000 & 1.00000 & - \\
\hline 100 & 0.99198 & 0.99198 & 0.99211 & 0.99202 & 1.3 & 0.99186 & 0.99120 & 0.99093 & 0.99133 & 9.3 \\
\hline 200 & .98103 & .98087 & .98122 & .98104 & 3.5 & .97968 & .97896 & .97907 & .97923 & 7.2 \\
\hline 300 & 96969 & 96937 & 96991 & .96965 & 5.4 & 96692 & 96639 & 96695 & 96675 & 5.6 \\
\hline 400 & .95781 & .95744 & .95822 & .95782 & 7.8 & .95392 & .95357 & .95426 & .95391 & 6.9 \\
\hline 500 & .94564 & .94531 & .94620 & .94571 & 8.9 & .94069 & .94059 & .94089 & .94072 & 3.0 \\
\hline 600 & .93321 & .93302 & .93390 & .93337 & 8.8 & .92732 & .92734 & .92693 & .92719 & 4.1 \\
\hline 700 & 92063 & 92065 & 92139 & 92089 & 7.6 & 91393 & 91394 & 91265 & 91350 & 12.9 \\
\hline 800 & .90795 & .90819 & .90875 & .90829 & 8.0 & .90033 & .90048 & .89857 & .89979 & 19.1 \\
\hline 900 & .89518 & .89530 & .89597 & .89548 & 7.9 & .88653 & .88690 & .88533 & .88628 & 15.7 \\
\hline 1000 & .88231 & .88225 & .88320 & .88258 & 9.5 & .87279 & .87319 & .87377 & .87325 & 9.8 \\
\hline
\end{tabular}

TABLE 2. Dependence of the elastic modulii of standard reference alumina bars upon temperature

\begin{tabular}{r|c|c|c|c|c}
\hline \hline \multirow{2}{*}{$\begin{array}{c}\text { Temp. } \\
{ }^{\circ} \mathrm{C} .\end{array}$} & $\begin{array}{c}\Delta l / l_{0} \\
\text { In Units of } 10^{-4}\end{array}$ & Flexure & Young's modulus & Torsion & \multirow{2}{*}{$\begin{array}{c}\text { Shear modulus } \\
\text { ratio }\left(G / G_{25}\right)\end{array}$} \\
& & $F_{Y}^{T}=\left(f / f_{25}\right)^{2}$ & & & \\
25 & 0.00 & 1.00000 & 1.00000 & 1.00000 & 1.00000 \\
100 & 4.63 & .99202 & .99156 & .99133 & .990087 \\
200 & 11.57 & .98104 & .97991 & .97923 & .97810 \\
300 & 19.24 & .96965 & .96779 & .96675 & .96489 \\
400 & 27.36 & .95782 & .95521 & .95391 & .95131 \\
500 & 35.80 & .94571 & .94234 & .94072 & .93736 \\
600 & 44.47 & .93337 & .92924 & .92719 & .92308 \\
700 & 53.29 & .92089 & .91601 & .91350 & .90866 \\
800 & 62.24 & .90829 & .90267 & .89979 & .89422 \\
900 & 71.19 & .89548 & .88915 & .88628 & .88002 \\
1000 & 80.19 & .88258 & .87556 & .87325 & .86630 \\
\hline
\end{tabular}

bricks and small openings stuffed with fiberfax insulation to minimize convective air circulation which could perturb the measurement.

Measurements were performed at different temperatures between 0 and $1000^{\circ} \mathrm{C}$. The furnace was held at a temperature until there was no further change in the frequency measurement (this was far more sensitive to small thermal changes than the thermocouples used) and the furnace had equilibrated at that temperature. The specimen temperature, differential output of the two end thermocouples, and frequency, first flexure then torsion, were obtained. Frequency was measureable to a reproducibility of at least one part in ten thousand, at a fixed temperature. Frequency measurements were performed with increasing and also decreasing temperature. The maximum deviation in temperature between the ends of the bar was about $2{ }^{\circ} \mathrm{C}$ and occurred at $500{ }^{\circ} \mathrm{C}$. Near room temperature the deviation was $0.1^{\circ} \mathrm{C}$, while at $950^{\circ} \mathrm{C}$ it was $1^{\circ} \mathrm{C}$.

The LDGO data were determined at 27 different temperatures. The frequency data for each mode were computer fitted to a polynomial expansion using a least square technique. The computer program employed for this purpose progressively increases the number of terms in the polynomial until one yielding the smallest errors is found, and the frequencies for the two modes are then calculated at selected temperatures using this polynomial.

\section{Experimental Results and Discussion}

Table 1 lists the values of $\left(F_{i}^{T}\right)^{2}$ calculated for selected values of temperatures. Results are listed for the two bars $(\mathrm{C}-7$ and $\mathrm{A}-1)$ measured at NBS and the results for bar A-1 determined at LDGO. The uncertainty assigned to the average values of the normalized frequency is the maximum spread of the values reported in the three sets of measurements. ${ }^{2}$ The Young's modulus and shear modulus based on the data presented in table 1 are given in table 2 . The values of $\Delta l / l_{0}$ for polycrystalline alumina is from Wachtman et al [6]. In using the NBS elasticity standards we recommend that measurements be compared directly with the frequency data reported in table 1 , as the moduli values also contain errors due to the thermal expansivity data, and the errors in the room temperature determination of the Young's and shear moduli.

The very close agreement of the results obtained with bars $\mathrm{C}-7$ and $\mathrm{A}-1$ at the same laboratory support our earlier statement that these data adequately describe the high temperature elastic properties of all

\footnotetext{
${ }^{2}$ The word "uncertainty" as used in this paper, means an estimated total uncertainty derived from the consideration of possible sources of error in all the measurements involved in the determination of the studied property. The estimation is generally based on previous knowledge of the measuring process involved; the estimates are not expressed in terms of exact statistical measures, such as standard deviations, because they comprise both random and systematic errors and are partly based on judgment rather than on repetitive measurements of the same quantity.
} 
the NBS test bars described in Part 1 [6]. On the basis of the interlaboratory results, it would appear that deviations between results on the same bar at different laboratories may be greater than deviations measured on any bars in the set of elasticity standards when measured in the same laboratory. The worst agreement is $9.5 \times 10^{-4}$ for the flexure and $19.1 \times 10^{-4}$ for the torsion, between any two individual measurements, and we recommend these as the minimum acceptable limits in using the standards.

The advantage of using the normalized frequency data for reference measurements is apparent in an examination of the data. Although different furnace designs, thermocouple arrangement, and loading conditions were employed at the two laboratories, these effects were removed by the process of normalization. However, it should be emphasized that considerable attention must be given to the furnace design, suspension, and thermocouple locations if satisfactory calibrations are to be obtained.

\section{Availability of Standard Bars}

This material is now offered by the National Bureau of Standards as Standard Reference Material number
718. Bars are now available from the Office of Standard Reference Materials, Room B314, Chemistry Building, National Bureau of Standards, Washington, D.C. 20234.

\section{References}

[1] Spinner, S., and Tefft, W.E., A Method for Determining Mechanical Resonance Frequencies and for Calculating Elastic Moduli from these Frequencies, Proceedings, American Society for Testing and Materials 61, 1221-1237 (1961).

[2] Dickson, R. W., and Wachtman, J. B., Jr., An alumina standard reference material for resonance frequency measurements and dynamic elastic moduli measurements. I. For use at $25{ }^{\circ} \mathrm{C}$, J. Res. Nat. Bur. Stand. (U.S.), 75A (Phys. and Chem.), No. 3, 155-162 (May-June 1971).

[3] Ault, N. N., and Ueltz, H. F. G., Sonic analysis for solid bodies, J. Am. Ceram. Soc. 36, 199-203 (1953).

[4] Spinner, S., Elastic moduli of glasses at elevated temperatures by a dynamic method, J. Am. Ceram. Soc. 39, 113-118 (1956).

[5] Dickson, R. W., and Spinner, S., An improved method for the determination of torsional and flexural resonance frequencies of cylindrical specimens, J. Mat. 3, 716-724 (1968).

[6] Wachtman, J. B., Jr., Scuderi, J. G., and Cleek, G. W., Linear thermal expansion of aluminum oxide and thorium oxide from $100 \mathrm{~K}$ to $1100 \mathrm{~K}$, J. Am. Ceram. Soc. 45, 319-323 (1962).

(Paper 77A4-778) 